\title{
Repository-Based Implementation of Information Pyramid: A Study Based on an ERP Case Study
}

\author{
Hans-Jürgen Scheruhn ${ }^{1}$, Daniel Ackermann ${ }^{1}$, Roman Braun ${ }^{1}$, and Ulrich Förster ${ }^{2}$ \\ ${ }^{1}$ Business Informatics, Media Informatics, Hochschule Harz, Friedrichstr. 57-59, \\ 38855 Wernigerode, Germany \\ \{dackermann, hscheruhn, u27077\} @hs-harz.de \\ ${ }^{2}$ Atos Werner-von-Siemens-Platz 1, 30880 Laatzen, Deutschland \\ ulrich.foerster@atos.net
}

\begin{abstract}
ERP case studies have an important impact on the transfer of knowledge between software vendor, lecturer and user. This paper describes to which extent ERP case studies can be used to demonstrate a repository based integrated approach for modeling and implementing the entire information pyramid in the context of the Business Process Management life cycle. The study is based on the Global Bike Inc. enterprise model repository created with ARIS Business Designer for SAP by Software AG. The information models have been exemplarily synchronized with SAP Solution Manager repository and implemented with SAP ERP respectively with SAP Netweaver BI.
\end{abstract}

Keywords: ERP case study, ARIS Business Designer, Business Process Management life cycle, SAP Solution Manager, SAP Netweaver BI, Sustainabilty Balanced Scorecard.

\section{$1 \quad$ Problem Identification}

ERP case studies are used for the transfer of knowledge in both the academic and the non-academic sector [17]. The authors state a lack of integration of strategic, tactical and operational business information models (entire Information Pyramid) as well as a lack of integration of its implementation with corresponding IT-Systems (entire business process life cycle) based on ERP case studies [21].

Scheruhn et al. [24] compared three different ERP case studies on the as-is status with each other regarding information model structures, information model types and information object types of the corresponding enterprise models [5; 30]. The comparison based on the GBI enterprise information model repository resulted in a common ERP case study framework which was worked out structurally in an evaluation matrix on the operational level.

A study about the possible enterprise information model structure of an integrated model based implementation of ERP case studies (to-be status / extended by future business objectives of tactical and strategic level) with the intention to create a common framework as repository for structured transfer of knowledge and for support of model based implementation in both the academic and the non-academic sector is yet missing. 


\section{Objective of a Solution}

ERP case studies support students learning the handling of different functional areas in a practical way [29]. Several ERP case studies exist, for example Global Bike Inc. [32], SSB Inc. [8], SAP TERP10 exercises at IDES AG [29], SAP Business ByDesign's ALMIKA Holding [14; 15] and OPM's IDES AG [23] which provide an introduction to different ERP systems of SAP.

This paper aims to investigate the information model based teaching of implementing ERP case studies (to-be status) in approach to further benefits. Consecutively existing ERP case studies (as-is status) are to be analyzed by students of business administration and/or business informatics as a basis for possible improvements (tobe status) and its implementation in the context of the business process life cycle [23].

The paper identifies all necessary information models based on an extended evaluation matrix created by the authors which can be used as a framework for further case study enterprise model or company enterprise model comparisons (e.g. ALMIKA Holding or VW Financial Service [31]). The integration of aspects of business and information technologies, of strategic, tactical and operational points of views as well as the integration of "actors", "business processes, business services and information flow" up to its implementation with ERP and BI systems in the context of the information pyramid in one single enterprise model is to be demonstrated [25].

\section{Design and Development}

\subsection{Constructs}

Software Reference models like the SAP Solution Manager Business Blueprint Repository [13] and/or Industry Reference models like Handels-H [2] provide support for construction processes of an individual enterprise model [5]. The enterprise models developed and evaluated in this paper are considered as integrated software-industry reference models which - in this case - depict typical company processes of the engineering industry based on software, e.g. SAP ERP. The IPR (Industry.PerformanceREADY) model is a good example [27] for such an integrated reference model approach which deals very successful in the non-academic sector. Compared to the GBI (to-be) enterprise model it covers most of the information models and objects of the evaluation matrix (see 5.) and additionally is connected with best practice KPI provided by APQC[1].

According to Scheruhn (Fig.1), the Business Process Management (BPM) life cycle encompasses five phases [23]. The main focus in this paper will be the integration of phases 2 and 3 whereas the previous paper [24] investigated phases 2 and 4 . Phases 2-5 are supported (but not fully integrated) by the SAP Solution Manager and SAP ERP. SAP BI covers all phases with data seen as important constructs of processes. 


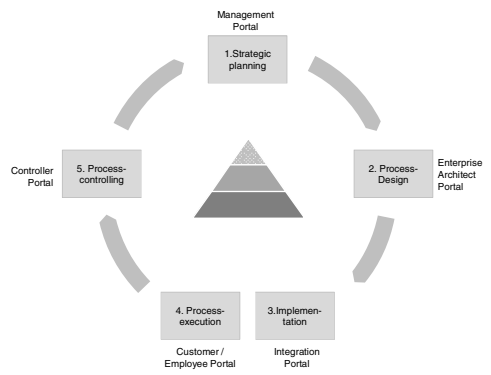

Fig. 1. Process life cycle with five phases by Scheruhn and Information Pyramid

\subsection{Information Pyramid}

The information pyramid is divided into three levels (Fig.1). The tactical level connects the strategic and the operational level [9]. The considered ERP case studies mainly cover the operational level in the context of the horizontal and vertical integration. In this study the tactical and strategic level on top also need to be considered. For implementing the corresponding tactical and strategic information models the authors additionally evaluated SAP Netweaver BI.

\subsection{Four IT Integration Layers}

In this research business processes are regarded as sub models of a model system, which includes: Subject-oriented modeling [26], Process-oriented modeling, Serviceoriented modeling [3], Enterprise data modeling [6].

This leads to four horizontal IT integration layers (1.Presentation, 2.Processes, 3.Functions and 4.Data) of the enterprise model (see Fig. 2) describing an IT system like SAP ERP or SAP Netweaver BI in its interaction with a specific enterprise. A vertical decomposition of each of the four IT integration layers leads to a model hierarchy of four additional levels shown in figure 2. These hierarchical levels can be mapped with the four process levels of the SCOR reference model [28] as well as partly with the three levels of the SAP Solution Manager Business Blueprint Architecture [13].

\subsection{Methods}

First a hypothesis is formulated which has to be reviewed in the course of this investigation [12] based on the implementation of the entire information pyramid exemplified with SAP ERP and Netweaver BI regarding the corresponding GBI enterprise model.

Hypothesis: The available GBI ARIS to-be enterprise model can be fully integrated into SAP ERP and SAP Netweaver BI including all necessary information models to form a common information model framework repository for structured transfer of knowledge and for support of model based implementation in both the academic and the non-academic sector. 


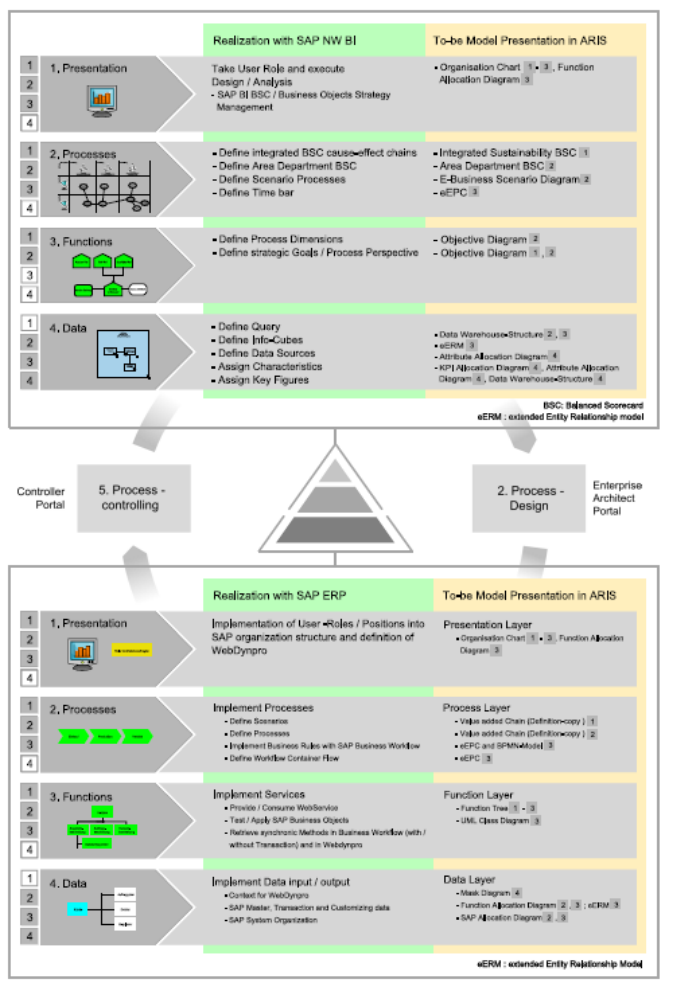

Fig. 2. GBI enterprise model for implementing SAP NW BI and for implementing SAP ERP [25]

Thus, it has to be proven to which extent SAP ERP and SAP Netweaver BI are able to interchange information model structures, information model and object types with ARIS Business Designer (BD) respectively SAP Solution Manager. These requirements will be worked out and compared in an evaluation matrix based on the following assumptions:

- SAP ERP and SAP NW BI applied together cover the entire Information pyramid and the entire Process life cycle

- SAP NW BPM is not considered because of focus on Core application without automization of Business Processes spanning different applications

- Single information models (phase two of Process life cycle) of the GBI enterprise model repository are provided completely but separately by SAP ERP and SAP NW BI

- Single information models of the GBI enterprise model repository based on ARIS Business Designer (BD) are entirely integrated in one enterprise model

- Information models of GBI based on ARIS BD and based on SAP ERP respectively SAP NW BI are equal but not directly integrated

- SAP Solution Manager serves as an interface between the information models of ARIS BD and SAP ERP respectively SAP NW BI 


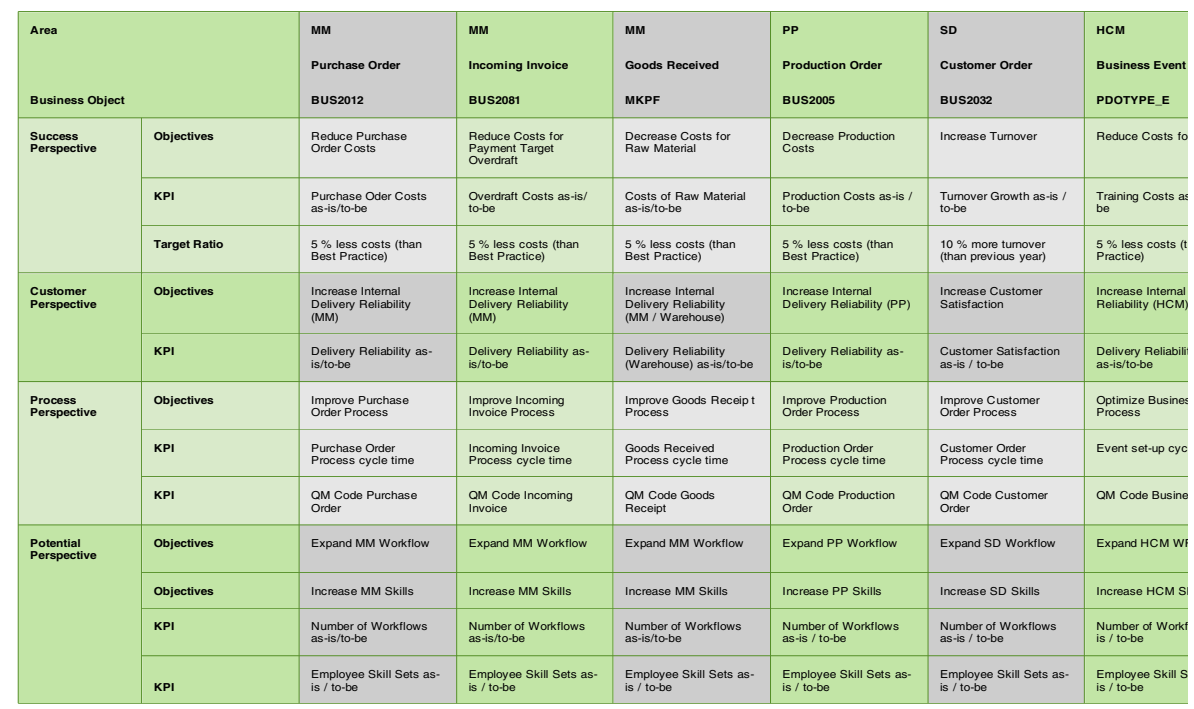

Fig. 3. Area Department Balanced Scorecards and corresponding SAP Business Objects

\subsection{Instantiation}

The GBI (Global Bike Inc) model company is situated in the manufacturing industry. It is a multinational enterprise producing and distributing bicycles. GBI is an international group with subsidiaries in Dallas, Miami and San Diego in the United States of America and Heidelberg and Hamburg in Germany. The GBI enterprise model and its implementation have been taught at the Hochschule Harz in a degree course of Business Informatics in 2012/2013 and its results have been documented by the students in a weblog [11], which contents can be found in Chapter 4. Relevant SAP ERP models used in this enterprise model are Materials Management (MM), Production Planning (PP), Sales and Distribution (SD), Human Capital Management (HCM) and Financial Accounting (FI). GBI 2.1 case study is hosted by SAP University Alliance [18]. SAP Solution Manager 7.1 as well as SAP ERP ECC 6.0 and SAP NW BI 7.0 (7.3 in progress) are hosted by SAP UCC Magdeburg [19]. As one of the most recognized performance measurement frameworks [20], the balanced scorecard is implemented on the strategic level based on the establishment of cause and effect chains between strategic objectives respectively key performance indicators. To improve the enterprise performance in all dimensions of sustainability (economic, ecologic and social) the pillars of sustainability are integrated in the successful realization of the enterprise strategy [4]. All department Balanced Scorecards of the GBI repository are connected via internal customer relationships [11] and organized as cost centers (except sales) pursuing department IT-strategies (expand implementation of workflows). To achieve a successful realization of the department balanced scorecards (economic pillar), business rules are implemented in terms of Quality Management codes [10]. The Compliance of these business rules and a constant 
comparison with best practices can be used as a key performance indicator in internal processes. This is done by a $100 \%$ integration of the strategic (top of fig. 2) with the operational models (bottom of fig. 2).

\section{Demonstration}

This section presents results of the first demonstration of above-mentioned ideas to implement an enterprise model repository based on the GBI model company. The corresponding blog "Online Process Management at GBI" has been posted in the SAP Community Network and currently consists of 4 (5 and 6 in progress) parts, which address following aspects of the enterprise model:

\begin{tabular}{|c|c|}
\hline $\begin{array}{l}\text { Online Process Management at GBI } \\
\text { / Part } 1[11]\end{array}$ & $\begin{array}{l}\text { GBI Business Process Management Life Cycle, GBI Enterprise Model, GBI Sustainability } \\
\text { Balanced Scorecard }\end{array}$ \\
\hline $\begin{array}{l}\text { Online Process Management at GBI } \\
\text { / Part } 2\end{array}$ & Harz Roadmap at SAP Solution Manager, GBI Business Blueprint goes ARIS \\
\hline $\begin{array}{l}\text { Online Process Management at GBI } \\
\text { / Part } 3\end{array}$ & $\begin{array}{l}\text { Business Workflow and NW BPM as a major step towards process automation at GBI, } \\
\text { How the Workflow works, Workflow Builder challenge }\end{array}$ \\
\hline $\begin{array}{l}\text { Online Process Management at GBI } \\
\text { / Part } 4\end{array}$ & WebDynpro goes iPhone, Responsive Frameworks at GBI \\
\hline $\begin{array}{l}\text { Online Process Management at GBI } \\
\text { / Part } 5 \text { (in progress) }\end{array}$ & Providing and consuming WebServices at GBI \\
\hline $\begin{array}{l}\text { Online Process Management at GBI } \\
\text { / Part } 6 \text { (in progress) }\end{array}$ & $\mathrm{BI}$ at $\mathrm{GBI}$ \\
\hline
\end{tabular}

Beginning with the WebDypro Context Diagram for future business the presentation design is capable of reacting to trends like mobile and ubiquitous computing.

For WebDynpro there are possibilities to design themes with stand-alone software, for instance with an Eclipse-Plugin (ThemeEditor32). On small high resolution displays information presented with "Portal Theme Editor" themes can result in a poor readability because of pixelation and small font sizes. It should be possible to implement a basic design reacting to different browser sizes.

This could be reached by taking advantage of technologies like responsive frameworks (e.g."Twitter Bootstrap" [33]), which is based on CSS3, Html5 and Javascript. At the present those frameworks are capable of "reacting" to user devices from smartphones up to large desktop by delivering the correct font size and layout. This responsiveness is an approach of web design providing an optimal viewing experience.

Like in Wroblewski [34] and Marcotte [35] described, the responsive design method scales the html content for a wide range of displays in a very ergonomic way. The integration of basic responsive technologies in WebDynpro could lead to even more user acceptance in terms of readability and overview. As a general example Figure 4 shows the same content on 3 different devices. 


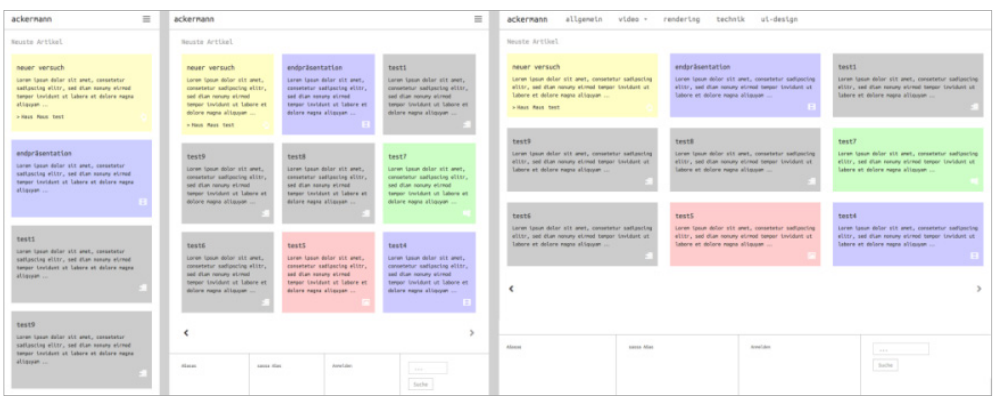

Fig. 4. Responsive layout presented on 3 different displays

\section{Evaluation Matrix}

An examination of the Enterprise Meta-Model (EMM) by Gudas [5] shows 8 different core objects (Actor, Process, Function, Information, Business Rule, Event, Objective and Material Flow), of which SAP Solution Manager is able to implement the first four, one per IT integration layer(fig.2). Thus, the Solution Manager offers a permeability of $50 \%$ of object types considering the Enterprise Meta-Model by Gudas. The following Evaluation Matrix extends the EMM with reference to information model and information object types and its instances found in SAP ERP (compare bottom of Fig. 2) and SAP BI (compare top of Fig. 2) that are necessary for implementing the to-be status of GBI.

A comparison of the integrated GBI ARIS repository in its to-be status with its distributed information model repository based on SAP ERP and BI shows 80/30\% distribution (overlapping of data layer). If combined, they are able to display all aspects of the information pyramid (SAP ERP on the operational level, SAP Netweaver BI on the tactical and strategic level) and all (ERP four, BI five) of the process life cycles by Scheruhn. All the four IT-integration layers as well as the four levels of hierarchy can be integrated into one ARIS BD repository. In summary it can be said:

- 8 (EMM) + 3 (GUI, Money, Location) object types found in SAP ERP (80\%) and SAP BI $(30 \%)$ with $10 \%$ overlapping of data layer = 11 object types

- All 11 object types integrated (related to each other) in 14 model types in one single GBI enterprise model in ARIS

- Only $50 \%$ of object types (in both EMM and EMM+) and 30\% of model types (EMM+) of ARIS integrated with SAP ERP / BI because of SAP Solution Manager restrictions:

- Business Blueprint not connected with SAP BI: (no Objectives, KPI)

- Business Blueprint covers only 3 of 4 hierarchy levels: (no Events, Business Rules, Money flow/material flow of ERP)

- Business Blueprint covers no object instances (e.g. no locations of enterprise) 
Table 1. Evaluation Matrix GBI (to-be)

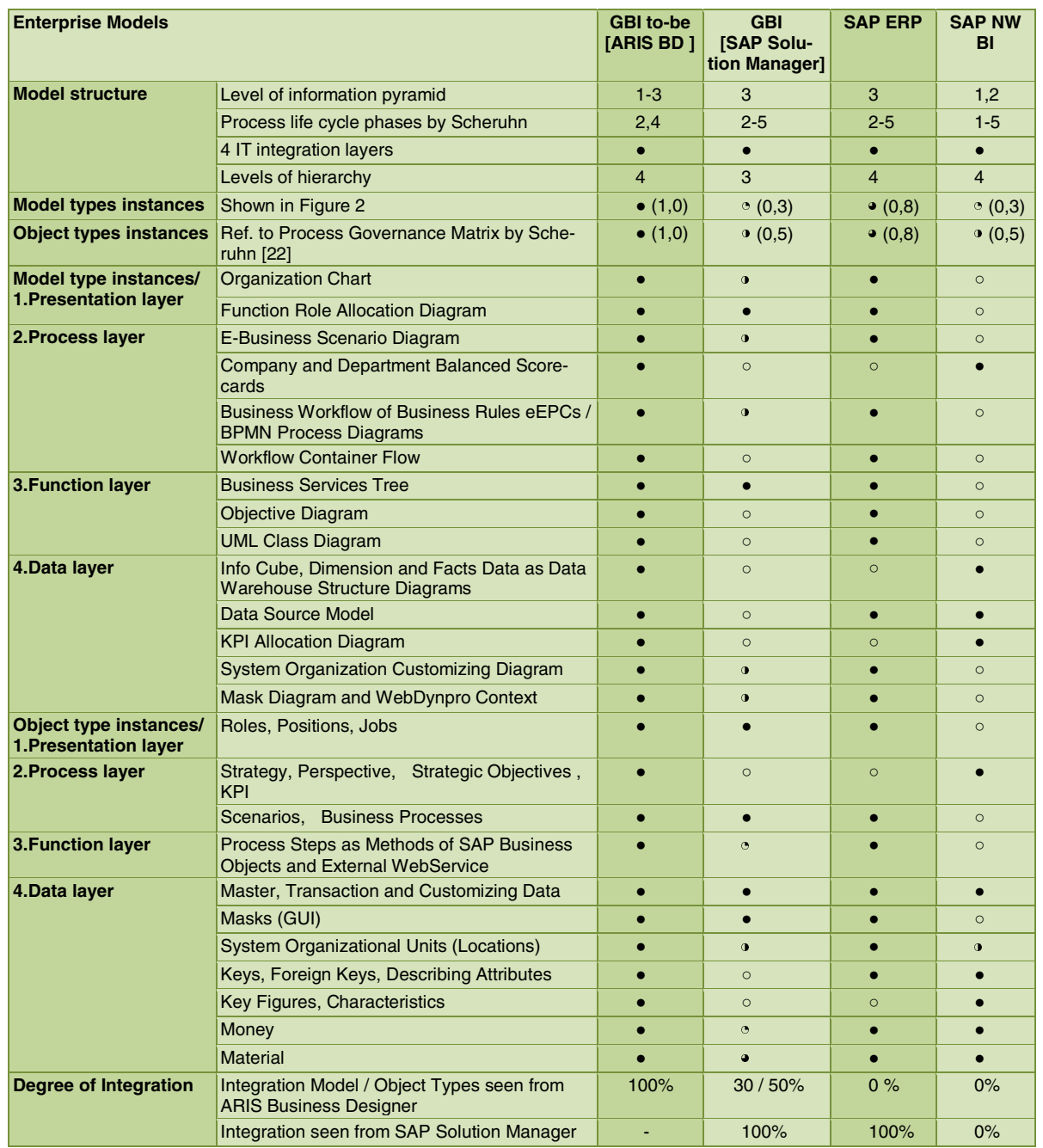

Legend : $\odot$ : available only via navigation into SAP ERP

- : no interconnection of objects (org structure, Flow of money/material, GUI I/O)

- : incomplete (no persons, no instantiation)

\section{Conclusion and Outlook}

The evaluation matrix identifies all necessary information models on the strategic, tactical and operational level to create a common framework as a repository for structured transfer of knowledge and for support of model based implementation in both the academic and the non-academic sector. First, all of the necessary model and object type instances found in SAP ERP and SAP Netweaver BI can be (partly manually) represented and integrated in one single enterprise model repository based on ARIS 
BD. Second, as they have to be imported from the ARIS BD through SAP Solution Manager, which serves as a highly integrated and powerful interface, only a fraction of the models and objects can be implemented. Seen from ARIS BD only about $30 \%$ of the considered model type instances and only about $50 \%$ of the object type instances can be synchronized with SAP Solution Manager, with no possibility to connect strategic or tactical model and object types. This fact is showing a need for improvement of integration of enterprise model repositories. The matrix therefore can be used for possible future improvements to show necessary steps in the creation of repository frameworks.

All information available of the GBI case study has been considered in the enterprise model. Concerning the non-academic sector it has to be noticed that the TOGAF [30] enterprise architecture reference model possibly covers more objects of a real enterprise architecture. Actually, the GBI enterprise model covers some aspects of Architecture Principles, 100\% of Business Architecture, about $70 \%$ of Information System Architecture, no Technology Architecture and about $50 \%$ of Architecture Realization.

"Considering the implementation of SAP projects at external customers of ATOS, it can be said, that the ERP system with its processes and master data (level 2 and 4) plays the dominant role. A mapping in ARIS, besides the positive effect of visualization may also represent a chance to already show possible future extensions of the Solution Manager." [36] The authors strongly believe that the enterprise information model based on ARIS BD also can help to indicate SAP HANA database relevant areas in SAP ERP and SAP BI since most foreign keys columns are integrated.

\section{References}

1. American Productivity \& Quality Center, Best Practice Knowledge Base (2013), http: / / www . apqc . org / APQC-knowledge-base

2. Becker, J., Schütte, R.: Handelsinformationssysteme, Redline, Frankfurt (2004)

3. Becker, A.: Nutzenpotentiale und Herausforderungen Serviceorientierter Architekturen. Gabler Verlag, Wiesbaden (2011)

4. Hahn, T., Wagner, M.: Sustainability Balanced Scorecard. von der Theorie zur Umsetzung, Universität Lüneburg (2001)

5. Gudas, S., Lopata, A.: Approach to Enterprise Modelling for Information Systems Engineering (2005)

6. Houy, C., Fettke, P., Loos, P., van der Aalst, W., Krogstie, J.: Geschäftsprozessmanagement im Großen in Wirtschaftsiformatik 06/11. Gabler Verlag (2011)

7. Hufgard, A., Krüger, S.: SAP Business by Design: Geschäftsprozesse, Technologie und Implementierung anschaulich erklärt: Galileo Press, Bonn (2012b)

8. Magal, S., Word, J.: Essentials of Business Processes and Information Systems. Wiley \& Sons (2009)

9. Mertens, P., Bodendorf, F., König, W., Picot, A., Schumann, M.: Grundzüge der Wirtschaftsinformatik. Springer, Berlin (2005)

10. Nüttgens, M. et al: Governance and Sustainability in Information Systems. Managing the Transfer and Diffusion of IT. In: IFIP WG 8.6 International Working Conference, Hamburg, (2011)

11. Online Process Management at GBI / part 1 to part 4

http: / /scn.sap.com/community/uac/blog/2012/10/29/

online-process-management-at-gbi-part-1 
12. Peffers, K.: A Design Science Research Methodology for Information Systems Research. Journal of Management Information Systems 24(3), 45-77 (2007)

13. SAP Bibliothek: Business Blueprint (2012a), http: / / help.sap.com/saphelp_sm32/helpdata/de/2a/ 62c33af63ae93ae10000000a11402f/content.htm

14. SAP: Business ByDesign - Referenzsysteme - Szenario-Überblick Strategische Bezugsquellenfindung, Rel. 3.5.ss (2012a)

15. SAP: Business ByDesign: Unternehmensprofil für ALMIKA Vers.3.5. (2012b)

16. SAP: Strategische Bezugsquellenfindung - Referenzsystem für SAP Business ByDesign, Rel. 3.5. (2012c)

17. SAP:TERP10 (2012d), http: / /www. sap. com/germany/services / education/globaltabbedcourse.epx?context=[ [|terp10|||||] ] |

18. SAP UCC Magdeburg (2013), http: / /www . sap-ucc . com/

19. SAP University Alliance: GBI 2.1 ARIS Repository (to-be status) (2013), http: / / sapschulungen.hs-harz.de/GBI_21_Sollzustand_en/index.htm

20. Schaltegger, S., Bennett, M., Burritt, R.: Sustainability Accounting and Reporting. Springer, Dordrecht (2006)

21. Scheer, A.-W., Habermann, F.: Making ERP a Success. Communications of the ACM 43(4), 57-61 (2000)

22. Scheruhn, H.-J.: Model Governance Matrix: ALMIKA (2012c), http: / /hscheruhn.hsharz.de/lehre/alle/Modell-Matrix_horizontale_Navigation.pdf

23. Scheruhn, H.-J.: Online-Prozessmanagement mit SAP ERP. In: Scheruhn, H.-J., Papenfuß, D., Funk, B., Niemeyer, P. (eds.) Modellierung und Implementierung von Geschäftsprozessen in verteilten Systemen, Dr. Kovac, pp. 141-177 (2010)

24. Scheruhn, H.-J., Sicorello, S., Weidner, S.: Repository-based ERP case studies: A study about chances and benefits of agile case study development. In: Abramowicz, W., Domingue, J., Węcel, K. (eds.) BIS 2012 Workshops. LNBIP, vol. 127, pp. 186-197. Springer, Heidelberg (2012)

25. Scheruhn, H.-J., Thielert, B., Weidner, S.: GBI-Unternehmensmodell/ Business Process Analysis/Soll-Zustand (2012b), http: / / hscheruhn.hsharz.de/lehre/alle/Intro_ERP_Using_GBI_Slides_BPA_de_v2.1_ Sollzustand_ARIS_final.pdf

26. Schmidt, W., Fleischmann, A., Gilbert, O.: Subjektorientierter Ansatz in Prozessmanagement: Praxis der Wirtschaftsinformatik. Heft 266 4/09 (2009)

27. Software AG: Industry.PerformanceREADY (2013), http: / / www . softwareag.com/ de/service/sap_consulting/ipr/default.asp

28. Supply Chain Council: SCOR-Referenzmodell (2012), http: / / supply-chain.org/scor

29. TERP10: SAP ERP - Integration of Business Processes (2012), http: //www.terp10.de/pages/deutsch/kurs.php

30. TOGAF: Module 7 TOGAF Content Metamodel (2013), http://www.togaf .org/ togafSlides91/TOGAF-V91-M7-Metamodel.pdf

31. Volkswagen Financial Services AG (2013), http://www.vwfsag.de/content/ sites/vwcorporate/vwfsag_de/de/home.html

32. Weidner, S., Magal, S., Word, J.: Global Bike Inc. Version 2.1. (2011)

33. Twitter Bootstrap, http: // twitter.github.com/bootstrap/

34. Wroblewski, L.: Mobile First. A Book Apart, New York, New York, USA (2011)

35. Marcotte, E.: Responsive Web Design. A Book Apart, New York, New York, USA (2011)

36. Förster, U: Interview at ATOS Hannover (January 28, 2013) 